\title{
Social Coordination, Self-Image, and Cooperation in Investment Games
}

\author{
Evelyn Korn $^{1}$, Stephan Meisenzahl ${ }^{1} \&$ Johannes Ziesecke $^{1}$ \\ ${ }^{1}$ School of Business \& Economics, Philipps University, Marburg, Germany \\ Correspondence: Evelyn Korn, School of Business \& Economics, Universitätsstr. 24, 35037 Marburg, Germany.
}

Received: July 7, 2015

Accepted: July 22, 2015

Available online: July 28, 2015

doi:10.11114/aef.v2i3.979

URL: http://dx.doi.org/10.11114/aef.v2i3.979

\begin{abstract}
Why do people cooperate in social groups? This paper provides experimental evidence that the fear of losing the self-image as a norm-compliant player might be one explaining factor. To that end an investment game with a public-goods character is played in different institutional setups that vary in the possibility to build reputation as well as in the communication of potential social norms. In addition, it provides a model that explains participants' decisions based on an extension of the neoclassical model. It covers a trade-off between pure wealth maximization and the minimization of damage to the self-image of being compliant. Experimental results show that this tradeoff is important in those treatments that allow for reputation building. We conclude that the wish to "do the right thing" can enhance cooperation in a socially stable environment.
\end{abstract}

Keywords: investment game, experiment, reputation, cooperation, norm compliance, institutional design

\section{Introduction}

The neoclassical reference model of the homo economicus has been challenged in the last decades by empirical as well as theoretical research. Empirical studies in the laboratory (see, for instance, Andreoni (1988), Forsythe et al. (1991), Hoffman et al. (1994), Keser and van Winden (2000)) and in the field (Henrich et al., (2001)) have shown that humans show more prosocial behavior than neoclassical models predict.

The classic test cases are dictator- or ultimatum games. Here, individuals claim a smaller part of the money to share than the Nash equilibrium predicts. Within public-goods games where the jointly optimal and the individually optimal contribution differ, the experiments show that individuals choose contributions between these two options.

These experimental observations have led to the hypothesis that people are not only interested in their own well-being, but also in the well-being of others. Theoretical models of this enlarged interest cover the inclusion of other people's utility in the individual's maximization problem, by a change of the fundamental self-interest assumption of neoclassical economics. In these models so called „other-regarding preferences“ cover an ideal of a fair distribution. These preferences address reciprocity and inequality aversion and replace the neoclassical objective function that is rooted in mere self-interest (See, for instance, Bolton, Katok, and Zwick (1998), Fehr and Gaechter (1998), Fehr and Schmidt (1999), Bolton and Ockenfels (2000), Fehr and Fischbacher (2002), Falk and Fischbacher (2006), Falk, Fehr, and Fischbacher $(2003,2008)$ on fairness, reciprocity, and non-selfish motives in general).

However, by doing so, the models use only parts of the information provided by the experimental results. If the difference between the neoclassical prediction and the observed behavior is a consequence of other-regarding preferences, the source is idiosyncratic. Yet, Henrich et al. (2001) hint to a driver outside the individual's sphere. In their cross-cultural comparison they show that the observed behavior differs across societies but is similar within each society. This result suggests that there is an institutional factor, a social coordination process that needs to be taken into account.

Based on this hypothesis we provide and test an alternative approach to the idea that individuals show other-regarding instead of purely self-interested preferences. In that we assume that individuals are still self-interested but react to social cues that induce a cost to choosing the Nash-equilibrium behavior. This idea adds to the strand of the literature that connects social coordination and individual behavior.

Hoffman et al. (1994) mention that experimental results are often driven by „,a social concern for what others may think" or by the wish to be „held in high regard by others“ instead of „fairness“" or „,other-regarding preferences“. Levitt and List (2007) use the idea of a moral cost as a driver for behavior. Bardsley (2008) points out that economic models have to account for the characteristics of context-specific social norms in behavior". Akerlof and Kranton $(2000,2005)$ 
as well as Sliwka (2007) model internal costs of choosing a socially undesirable action.

This paper focuses on the question of how the coordination of individual behavior actually works. We test the influence of norms and reputation in an investment game with public-goods character. The observed behavior is explained by a model that allows for a connection of idiosyncratic characteristics and contextual effects of social cues. The explanation is based on a model that is developed and analysed in a companion paper by Ziesecke (2015). It covers the impact of social coordination in two ways: It includes a factor that introduces perceived socially desirable behavior into the utility function. In addition, it measures the factor's actual impact on a particular decision by a separate parameter that may cover timing aspects as well as other personal or exogenous factors.

These two factors can be nicely used within a public-goods game which is a classical way to test the level of cooperation in an experimental frame (see, for a classic description, Andreoni (1988), Keser and van Winden (2000)). In these games all players can contribute to a joint project. The neoclassical analysis predicts an underinvestment problem as individual contributions benefit all players while costs are borne by the contributor alone. Laboratory experiments typically show that participants contribute more than the neoclassical model predicts but less than would be socially desirable. Experiments also show that contributions are closer to the social optimum when the game is repeated within the same group of players. In such a scenario, players can build a reputation for cooperative behavior. In addition, pre-play communication can be adapted such that a certain behavioral expectation is established.

We use treatments that play with the reputation- as well as the pre-play-communication aspect to show that players account for the two factors named above: By varying the communication between experimenter and subjects we introduce a social cue that influences the behavior players perceive as expected (or at least accepted); by varying the possibility of reputation building we influence the importance of social coordination.

This setting allows to separate players' reactions to changes in each of the parameters separately. The model predicts a change in the average contributions to the public good. They might, starting from an intermediate baseline level, move towards the Nash prediction or towards the social optimum.

To analyze the effects of social cues and reputation building, we designed four different treatments based on the original public-goods game. The treatments differed in the pre-play preparation of the participants and in player matching: in the basic treatment, we only checked if participants had understood the rules of the game; in the guided treatment, participants learned how to deduce the Nash-equilibrium of the game as well as the socially desirable outcome. Participants played the game 20 times. Both scenarios used a partner design, where player pairs were the same in all 20 rounds, and a random stranger design, where pairs were matched anew in each round. The random stranger design can be seen as a repeated one-shot game without the possibility to build a reputation, while the partner design imposes reputation building. By this variation we aimed at measuring the importance of the social cue.

Our results show that a change in the social cue can support cooperative play. The choice of contributions is significantly higher in the guided treatment with partner design than in the basic treatment with partner design. The identification of a selfish strategy (the Nash equilibrium strategy) and a group-oriented strategy (the socially optimal strategy) does change the individual perception of socially accepted behavior. Anyway, this change has no effect on individual behavior when reputation building is not imposed. So, we see that people want to "do the right thing" or, to frame it differently, keep up a self-image as a socially compliant person.

What is important here, is that the change in players' perception has been caused by an outside force. For that reason it can be included as a control variable in the analysis of the experiment.

Our results suggest that the behavior of individuals in economic experiments does not challenge the selfishness assumption. By use of the enlarged model the observed behavior in all four treatments can be explained as a result of self-interested utility maximisation under constraints. The guided treatment makes expected behavior more visible to the players themselves; the partner treatment makes sure that others will be able to see oneself's compliance. Both together drive the willingness to show cooperative behavior.

This insight can be helpful in focusing the ongoing debate regarding selfish behavior on the core problem: Finding institutions that support reputation building and let people deal with time horizons correctly.

\section{Introduction of the game}

\subsection{Basic Model}

Individuals in our experiment are grouped into four treatments. All treatments are based on a bilateral game wherein each player (named $i$ and $j$ ) can contribute $R\left(z_{i}, z_{j}\right)$ to a project with joint revenue, where $z_{i}$ denotes $i$ 's nonnegative investment and $z_{j}$ denotes $j$ 's nonnegative investment. Each player receives half of the project revenue. We assume $R\left(z_{i}, z_{j}\right)$ to be twice differentiable, increasing, and concave in investments. Contributions are relation specific and exhibit mutual positive externalities on each partner's productivity. That is, 


$$
R\left(z_{i}, 0\right)=R\left(0, z_{j}\right)=0,\left.\quad \frac{\partial R}{\partial z_{i}}\right|_{\left(0, z_{j}\right)} \square 0,\left.\quad \frac{\partial R}{\partial z_{j}}\right|_{\left(z_{i}, 0\right)} \square 0 \text {, and } \quad \frac{\partial^{2} R}{\partial z_{i} \partial z_{j}}=\frac{\partial^{2} R}{\partial z_{j} \partial z_{i}}>0 \bullet
$$

Investments are costly and costs must be borne by each player individually, where the cost function $c$ (? is increasing and convex. Given this structure, investments are contributions to a public good within the relationship.

The total profit from cooperation is $\pi=R\left(z_{i}, z_{j}\right)-c\left(z_{i}\right)-c\left(z_{j}\right)$. Accordingly, first-best (cooperative) investments are characterized by $\partial R / \partial z_{i}=\partial c / \partial z_{i}$ and $\frac{\partial R}{\partial z_{j}}=\frac{\partial c}{\partial z_{j}}$.

A free-riding problem arises as revenue from the final product will be split equally between both partners and each partner must cover his investment cost. Individually-rational levels of investment are characterized by

$$
\partial R / \partial z_{i}=2 \partial c / \partial z_{i} \text { and } \partial R / \partial z_{j}=2 \partial c / \partial z_{j} \text {. Due to concavity of the production function, these investment levels are }
$$

lower than first-best levels.

As other authors have shown (Andreoni (1995), Ledyard (1995), et al.), players in an experiment typically choose investment levels between the cooperative and the individually-rational level. Our experiment aims at explaining the distance to both extremes. If a change in the institutional set-up changes the level of investment that players will choose, we will be able to use this variation to analyse features of the utility function (see section 2.3 for details on the experimental design).

We designed the production problem so that cooperative and individually rational investment levels were at a considerable distance. This was done to avoid focal points in the investment pattern and to make the variations resulting from different treatments visible. The revenue and cost functions used in all treatments were: $R\left(z_{i}, z_{j}\right)=54.1\left(z_{i} z_{j}\right)^{0.29}$, $c\left(z_{i}\right)=2 z_{i}$, and $c\left(z_{j}\right)=2 z_{j}$.

Accordingly, first-best investment levels are given by $z_{i}=z_{j}=134.87$ and individually-rational levels by $z_{i}=z_{j}=25.89$.

The neoclassical formulation is based on the assumption that players expect selfish utility-maximising behavior from each other and that, thus, Nash-equilibrium play is socially acceptable. We are interested in understanding how a social cue that changes the perception of socially accepted behavior affects player behavior in the given investment context. To that end we provide a model extension that covers social coordination.

\subsection{Model Extension}

The model presented here is based on the extension of the neoclassical model to the reference-dependent-preferences model provided by Ziesecke (2015) fitted to the current scenario. In this general model player $i$ receives utility based on the neoclassical payoff $R\left(z_{i}, z_{j}\right)$ as before. However, this payoff is adjusted by a factor that measures compliance to socially expected behavior. Each player maximizes an expected utility function

$$
U^{i}\left(z_{i}, z_{j}\right)=R\left(z_{i}, z_{j}\right)-\mu_{i}(\theta)\left(z_{i}-z_{j}\right), \quad i=1,2, i \neq j,
$$

where $\mu_{i}(\theta) \in[0,1]$ measures the importance player $i$ attaches to compliance.

The first part of the utility function yields the monetary payoff from the investment game. The second part of the utility function consists of two parts: a measure for the perceived socially accepted behavior - which takes the very simple form $z_{i}-z_{j}$ to evaluate the experiment (a more general formulation is used in Ziesecke (2015)). We assume that players take the other player's investment as an assessment of the socially expected contribution. Individuals perceive themselves as socially compliant if they contribute at least as much as the other player. In addition, the factor $\mu_{i}$ (which varies with the institutional-frame parameter $\theta$ ) measures the importance each individual attaches to being socially compliant. This parameter is used to connect individual and social context. For, the variation of the institutional frame used in the experiment allows for a utility gain from "doing the right thing" as well as "being seen as doing the right thing". We adopt this letter stance which distinguishes the social-compliance concern from actual other-regarding preferences as modelled in the literature.

As being seen as socially compliant depends on the chance to meet the other player again, we use experimental treatments that provide variation in that respect: in the random stranger design participants will not be able to observe the other player's past actions. In the partner design they will play the game in fixed pairs and, thus, know for sure that they will meet their current partner again and will be able to evaluate past actions. Accordingly, we assume that $\mu_{i}$ (random stranger $)>\mu_{i}$ (partner $)$. To place zero importance on social coordination will transform the decision problem into a neoclassical wealth maximization problem with the Nash solution. 
Taking our specifications into account, an individual in our investment game with public-goods character maximizes her expected utility function

$$
U^{i}\left(z_{i}, z_{j}\right)=\frac{54.1\left(z_{i} z_{j}\right)^{0.29}}{2}-2 z_{i}-\mu_{i}(\theta)\left(z_{i}-z_{j}\right)
$$

where $\theta \in\{$ random stranger, partner $\}$.

Taking derivatives yields the condition $\frac{\partial R}{\partial z_{i}}=2\left(\frac{\partial c}{\partial z_{i}}-\mu_{i}(\theta)\right)$ which is exactly the condition for individually rational contributions from page 147 if $\mu_{i}(\theta)=0$. Calculating Nash-equilibrium contributions in this modified game, we find

$$
z_{i}^{*}=\left(\frac{2-\mu_{i}(\theta)}{7.8445}\right)^{-\frac{0.5041}{0.2982}}\left(\frac{2-\mu_{j}(\theta)}{7.8445}\right)^{-\frac{0.29}{0.42}},
$$

where $i, j=1,2, i \neq j$. The optimal contribution of player $i$ is increasing in $\mu_{i}$ as well as in $\mu_{j}$.

Therefore, the model extension explains contributions higher than the neoclassical Nash-equilibrium contributions and predicts that players will choose higher investment levels in the partner design than in the random stranger design. If $\mu_{i}$ $=\mu_{j}$, players would choose socially optimal investments.

In the current context we are not interested in detailed features of the model extension (for a detailed discussion of model properties see Ziesecke (2015)). It is presented here to show how social concerns can be included into a model of selfish players. In addition, it allows for a separation of, on the one hand, the perception of a certain behavior that is considered socially compliant and, on the other hand, the importance of actually being seen as socially compliant. This differentiation is used in the experiment.

\subsection{Experimental Design}

To test how the institutional frame influences individual contributions in the investment game described above, we conducted a series of computer-based laboratory experiments with four different treatments using z-Tree (Fischbacher (2007)). Each subject in the experiment played a 20-round repeated game with simultaneous investment decisions in each round; (interim) payoffs were determined based on the above revenue and cost functions. To provide participants with a clear representation of the strategic situation, we reduced the continuous investment problem to a discrete one where participants could choose investment levels of $0,10,20, \ldots, 200$ points. Participants received a printed table showing his/her payoff in the one-shot game based on both players' contributions. (Note 1) In addition, participants had colored-paper positioning devices to support readability of the table. In the discrete game $z_{i}=z_{j}=130$ points were first-best investments and $z_{i}=z_{j}=30$ points as well as $z_{i}=z_{j}=20$ points were individually-rational investment levels. In each round participants had a budget of 200 points which could not be transferred between rounds. Participants chose their contribution by use of an input mask. When both players had entered their investment level, the computer program displayed the contributions, revenues, costs and payoffs of both participants.

Final monetary payoffs for participants were based on individual results in 5 randomly drawn rounds of the game. These rounds were drawn at the end of the experiment and were displayed alongside the outcomes and payoffs of all rounds. (Note 2)

To test the effects of the two aspects of social coordination introduced in the model extension, the treatments differed in two ways (see Table 1): the matching procedure (partner design and random-stranger design) and the pre-play preparation. In the partner design, subjects were randomly matched into fixed and anonymous pairs for the duration of the 20-round investment game. Subjects in the partner design knew that they were playing against the same participant in every round. This design was supposed to correspond to a higher importance of being seen as socially compliant, i.e., a high $\mu_{i}$. In the random-stranger design (which had more participants due to the needs of the matching procedure), pairs were randomly matched in each of the 20 rounds out of a fixed and anonymous group of 6 participants. Subjects in the random-stranger design knew that they would face different participants in each round. Accordingly, players could not expect recognition of social compliance, which would translate in a low $\mu_{i}$.

Table 1. The four different treatments

\begin{tabular}{lcc}
\hline & Partner Design & Random Stranger Design \\
\hline Basic Treatment & 48 Participants & 72 Participants \\
Guided treatment & 46 Participants & 120 Participants
\end{tabular}

The two different subject groups were exposed to two different kinds of pre-play preparation: A basic treatment and a guided treatment. (Note 3) In the basic treatment, the reading of the instructions was followed by a computer-aided test. This test ensured that participants knew how to read the payoff table, but did not hint at strategic considerations. The 
game started after all participants had completed this test. In the guided treatment, participants took part in a short practice session after the comprehension test. In this session they were asked questions like „What would be your payoff if you contribute 60 points and the other participant contributes 200 points?“ followed by the question „Assume you contribute 60 points. Which contribution should the other participant choose to reach the highest possible payoff?". All questions hinted at best responses to develop a possible dynamic towards the Nash-equilibrium. Additional three questions were asked focusing on cooperative investments: „Assume you could write a binding contract on contributions with the other participant. Which contributions would you choose if you were interested in the highest-possible payoffs for both of you?“", „What is your payoff if you and the other participant choose a contribution of 130 ?" and „Assume you expect the other participant to contribute 130 points. Which contribution would you choose if you were interested in the highest-possible payoff?"“. With these questions we produced a social cue that supported social coordination for the participants. The design of this pre-play information helped the participants to recognize the two extreme scenarios (selfish and cooperative behavior) and the potential loss of the Nash-equilibrium solution compared to the social optimum. That way the perception was reinforced that cooperation was the socially accepted behavior.

We conducted the experiments with students at Philipps-Universität Marburg. Of the 286 subjects, $67 \%$ majored in business administration or economics; the others majored in social sciences or humanities, with a small fraction from the life sciences. (Note 4)

\section{Experimental Results}

Previous work suggests that the majority of investments in a public-goods game should range between the Nash-equilibrium and the cooperative contribution. We augment this hypothesis by the claim that a social cue and the possibility to be seen as behaving socially compliant, further on denoted as reputation building, will shift the distribution of investments towards the cooperative level. We begin with a descriptive statistics of the outcomes to get a general understanding if this enlarged hypothesis is sound. Figure 1 shows the relative frequencies of different investment levels in all rounds ordered by treatments.

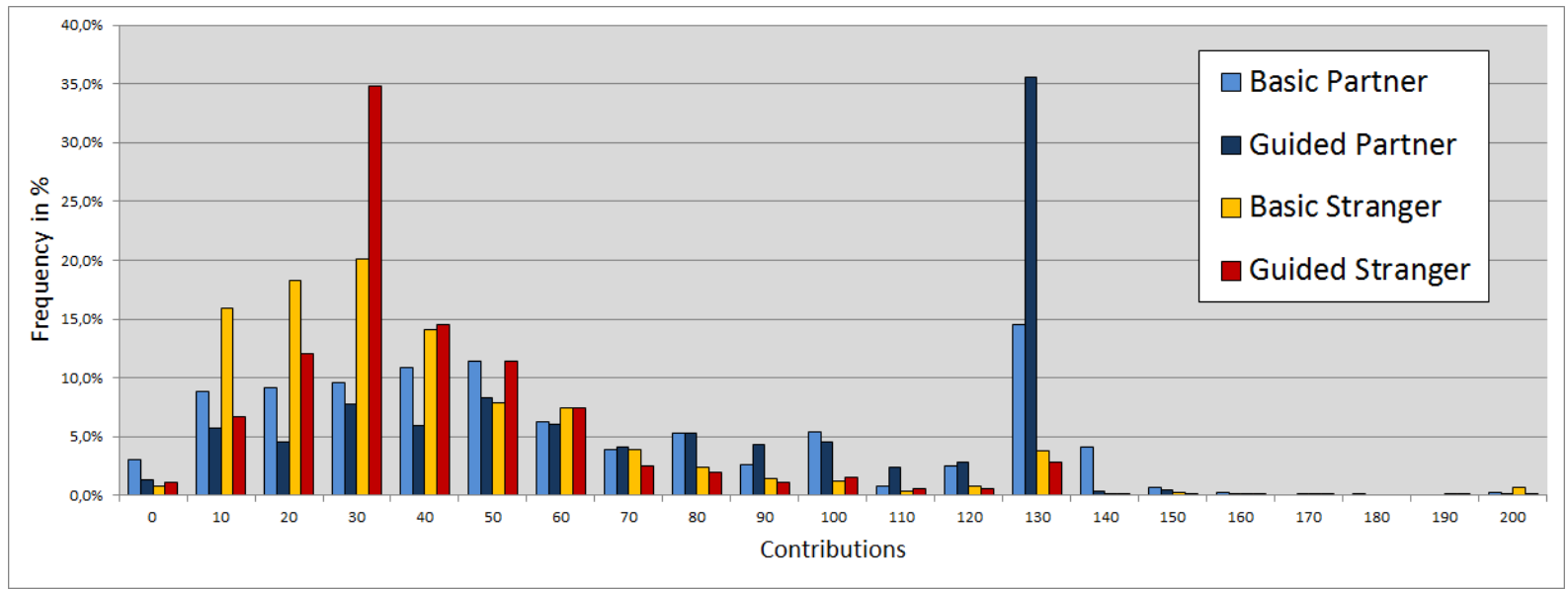

Figure 1. Relative frequencies of individual contributions

We see that reputation building has the expected effect. In the two random-stranger treatments, the majority of investments are distributed around the Nash-equilibrium levels with a clear peak at the Nash equilibrium of 30 points. In contrast, the partner treatments that allow for reputation building, show two peaks: One at around the individually-rational (Nash-equilibrium) investment level of 30 points and one at the first-best (cooperative) investment level of 130 points, with the highest peak in the guided treatment in partner design. The social cue thus has an effect on individual behavior when reputation building is possible.

Figure 2 shows the time structure of investments. The last rounds (17-20) show average investments that are near the Nash-equilibrium-level. Here the play clearly suffers from an endgame effect. Before this endgame effect kicks in, we see visible differences in the average contributions of the partner-design treatments.

None of these effects can be seen in the random-stranger treatments. The relative frequency of contributions around first-best investment levels remains very low throughout all rounds. The average contributions in the random-stranger treatments are clearly lower through all rounds, and no endgame effect can be found. Thus, the random-stranger design can be considered as a repeated one-shot game. 


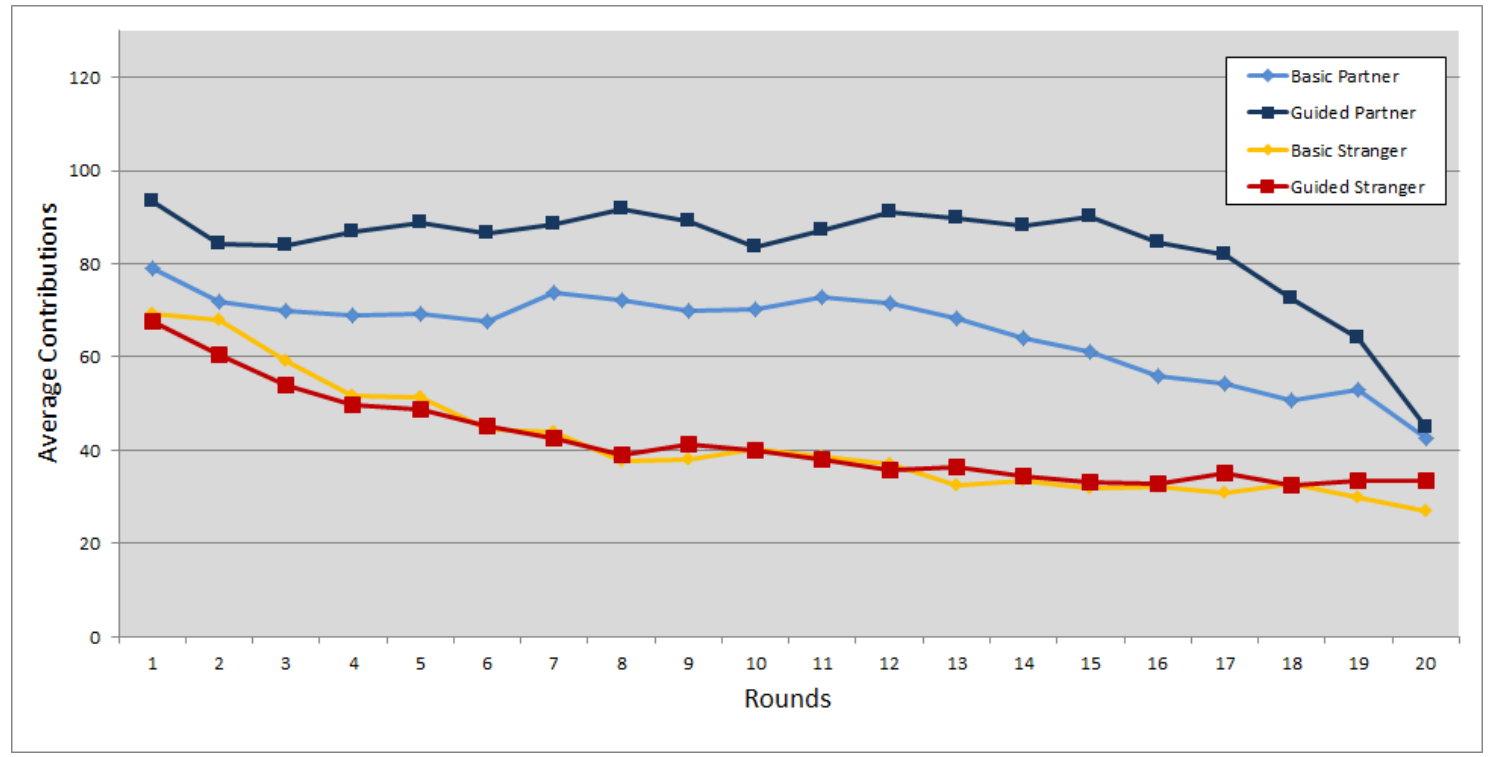

Figure 2. Average contributions over time

The descriptive part of the analysis supports the idea that the social cue enhances cooperative behavior. To analyze the effect in more detail, we formulate a set of hypotheses on the impact of that change and reputation building. First we determine whether the cue increases cooperation in the partner designs. Later we test whether the matching procedure impacts behavior, that is, if individuals behave differently in the basic partner design than in the basic random-stranger design.

To assess the effect of a social cue in the partner design, we test:

$\boldsymbol{H}_{\boldsymbol{0}}$ : The average contributions in the basic treatment under partner design and the guided treatment under partner design have an identical distribution.

$\boldsymbol{H}_{1}$ : The average contributions in the basic treatment under partner design are stochastically smaller than in the guided treatment under partner design.

If $\boldsymbol{H}_{\boldsymbol{0}}$ can be rejected, we can conclude that the additional questions in the pre-game preparation that provide a cue for corporation impact individual decision making and enhance cooperative play.

We use a two-sided Wilcoxon rank-sum test to test these hypotheses. The test statistics are given in Table 2. (Note 5)

Table 2. Difference in contributions over partner treatments

\begin{tabular}{lc}
\hline & $\begin{array}{c}\text { Basic (P) vs. } \\
\text { Guided (P) }\end{array}$ \\
\hline Test stat. & -2.64 \\
P-value & 0.0083 \\
\hline
\end{tabular}

Critical values are -2.58 for the $1 \%$ significance level, -1.96 for the $5 \%$, and -1.64 for the $10 \%$ significance level. Accordingly, there is a significant difference between the basic and the guided treatment.

We test the same hypothesis for the random-stranger design to check if the social cue has an effect on individual behavior when the opportunity of reputation building is reduced:

$\boldsymbol{H}_{\boldsymbol{0}}$ : The average contributions in the basic treatment under random-stranger design and the guided treatment under random-stranger design have an identical distribution.

$\boldsymbol{H}_{1}$ : The average contributions in the basic treatment under random-stranger design are stochastically smaller than in the guided treatment under random-stranger design.

If $\boldsymbol{H}_{\boldsymbol{0}}$ could be rejected, we could conclude that the cue has an impact on individual decision making even without reputation building. However, as expected from the descriptive statistics, we cannot reject the hypothesis. The test statistics are given in Table 3 . 
Table 3. Difference in contributions over stranger treatments

\begin{tabular}{lc}
\hline & $\begin{array}{c}\text { Basic (S) vs. } \\
\text { Guided (S) }\end{array}$ \\
\hline Test stat. & 0.94 \\
P-value & 0.3472 \\
\hline
\end{tabular}

All results so far suggest that the option for reputation building is a necessary ingredient for cooperative behavior. The repeated interaction provides the necessary platform to encourage individuals to play cooperatively as they can be seen as doing so. To complete this picture, we test the effect of the matching procedure on individual behavior in both treatments. The hypothesis to be tested is:

$\boldsymbol{H}_{\boldsymbol{0}}$ : The average contributions in the basic treatment (the guided treatment) under partner design and the basic treatment (the guided treatment) under random-stranger design have an identical distribution.

$\boldsymbol{H}_{1}$ : The average contributions in the basic treatment (the guided treatment) under partner design are stochastically higher than in the basic treatment (the guided treatment) under random-stranger design.

If $\boldsymbol{H}_{\boldsymbol{0}}$ can be rejected we can conclude that the different ways of matching have an impact on individual decision making. The test statistics are given in Table 4.

Table 4. Difference in contributions between partner and stranger design

\begin{tabular}{lcc}
\hline & Basic (P) vs. & Guided (P) vs. \\
& Basic (S) & Guided (S) \\
\hline Test stat. & 4.56 & 7.53 \\
P-value & $<0.0001$ & $<0.0001$ \\
\hline
\end{tabular}

As expected, the differences between the two matching procedures are indeed significant for both treatments.

The results show that a social cue can change individual behavior. Capturing this effect requires a stable group structure that facilitates reputation building. The driving force in the development of cooperative behavior is reputation building as the anonymous selection of participants eliminates the potential for the external support for individual self-image as socially compliant. Therefore, a social cue in a socially stable environment can have a positive value, while it has no effect in unstable environments that do not promote reputation building.

This interpretation is supported by the following observation: a clear end-game effect can be seen in the partner-design treatment that is much stronger in the guided group than in the basic group while the final-period contributions are identical between these two groups. As the fear of losing reputation is lower in the last rounds, this behavior suggests that people in the guided group are not truly cooperative but expectation-driven selfish. This observation supports the hypothesis that the social cue influenced people's fear of „doing the wrong thing“, but not their willingness to cooperate in principle. This change supports the interest in reputation building.

To ensure that the driving forces in our results were actually the two factors under consideration, we tested against other influences. We tested whether education or gender impacts the willingness to cooperate. We found no significant differences in the average contributions of economics and business students compared to students from other social sciences. Nor did we find a significant difference between female and male participants. (Note 6)

\section{Discussion}

The results of the experiment have shown that the behavior of individuals is influenced by experiences in the pre-play preparation and the possibility of building reputation. The fear of losing reputation, following from not being seen as acting like I should act, can be an explanation for the observed behavior. We conclude that people are driven by the wish to do the right thing. This wish is represented by a tradeoff between monetary gains and costs from a damaged self-image following from selfish behavior. The paper provides a model that separates the tradeoff into two separable factors: an institutional aspect covering the option to actually build reputation, in the experiment covered by variation in the matching of participants; in addition, the provision of the social cue that reveals socially desirable behavior to the participants, in the experiment provided by pre-play information on features of the game played.

To test both factors separately, we designed four different treatments of the game. Scenarios with differences in the pre-play preparation have been combined with two different matching procedures: (1) a random-stranger design, in which participants played against a different opponent in each round and (2) a partner design, in which participants played against the same partner in each round.

The random-stranger design without the guided questions resembles the structure of previous experiments (for instance, Croson (1996)). In line with their results we find that most participants chose contributions just slightly above the one-shot Nash-equilibrium prediction. Also in line with previous findings the average contribution increased in the 
partner design - thus, the option to build a reputation is valuable in itself.

The effect gets amplified by a social cue. For, the inclusion of guided questions that illustrated the Nash-equilibrium as well as the socially desirable (first-best) contribution and the payoff difference between these two, has had different effects in the two matching scenarios. While it did not change behavior in the random-stranger design, it increased cooperation in the partner design. Here, ,increased cooperation“ has two effects: More people have chosen first-best investments and the average contribution has increased for all participants.

These results suggest that a social cue raises individual awareness regarding the reputational cost of exploiting a project partner. These costs are only relevant in a situation that imposes reputation building: the partner design in the experiment.

We would like to stress that the guiding questions did not direct individuals to selfless and easily exploitable cooperative behavior. The practice instructions focused on best responses. The questions made individuals aware of the possible ways of playing. Individuals received a hint on what might be helpful social coordination, that is, what might be the "right thing to do". It did not actively lead people away from following their personal objectives. Therefore, the results suggest that the fear of losing reputation is what actually leads individuals to play cooperatively when they knew they would meet the other player again.

\section{Conclusion}

Our results support the view that institutional design is a relevant factor in determining the outcome of economic interactions and present a new perspective on helpful institutions. They confirm the accepted fact that long-term relationships provide incentives for mutually beneficial behavior. In addition, we see that people put less emphasis on short-term gains if they fear the long run costs of reputational losses.

One insight from the experiment is that, next to a good institutional design, cues for social coordination can enhance cooperation in a social group.

In contrast to the public perception of strategic thinking, the experiment suggests that economic thinking does not make people more egoistic. It can also help people to understand the long-term costs, following from short term gains. If it is common knowledge that a society would be better off if people did not maximize their short-term gains, social coordination in a stable environment is supported. The fear of not doing the right thing can impact economic decisions in that sense that pure wealth maximizing is more costly than cooperation.

These concerns define a reasonable frame for self-interest that has cooperative effects. The experiment shows that people are able to understand the social context of a decision and that short-run egoistic behavior has an adverse effect in the long run; therefore, it is not in the overall individual interest. Short-run oriented behaviour destroys own reputation (and self-image) as socially compliant and leads to less cooperative behavior in the group. The effect was triggered by a small intervention that emphasized the difference between individually and socially optimal behavior.

The experimental outcome therefore suggests that cooperation in groups can be enhanced if people receive information on the outcome of the game actually played. A policy implication would be to increase and improve public communication on the value of public goods and the long-run danger caused by free riding.

This result depends on an additional crucial assumption: Institutions need to be designed in a way that allows for reputation building. The basis for more cooperative (and mutually beneficial) behavior depends on the actual existence of these reputation concerns. How to design institutions that establish the stable social environment needed for these trade-offs is an issue beyond the scope of experiments on individual behavior.

\section{Acknowledgments}

We thank Lillie Crowley, Guido Friebel, Claudia Keser, Michael Naef, Michael Perdue, Volker Robeck, the participants of the 2012 ESA conference in New York, and seminar participants at 2010 FMA annual meeting as well as Philipps-Universität Marburg-Toyo University Symposium 2010 on Economics and Institutions for helpful comments and discussions. We thank Jascha Kristek, Julia Seider, and Lea Thiel for valuable research assistance. Financial support from Deutsche Bundesbank (without any influence in form and content) is gratefully acknowledged.

\section{References}

Ahmed, A. (2008). Can education affect pro-social behavior?: Cops, economists and humanists in social dilemmas. International Journal of Social Economics, 35(4), 298-307. http://dx.doi.org/10.1108/03068290810854565

Akerlof, G. A. \& Kranton, R. E. (2000). Economics and identity. The Quarterly Journal of Economics, 105(3), 15-753. http://dx.doi.org/10.1162/003355300554881

Akerlof, G. A. \& Kranton, R. E. (2005). Identity and the economics of organizations. The Journal of Economic Perspectives, 19(1), 9-32. http://dx.doi.org/10.1257/0895330053147930 
Anderson, L. R., DiTraglia, F. J., \& Gerlach, J. R. (2011). Measuring altruism in a public goods experiment: a comparison of U.S. and Czech subjects. Experimental Economics, 14(3), $426-437$. http://dx.doi.org/10.1007/s10683-011-9274-8

Andreoni, J. (1988). Why free ride? Strategies and learning in public goods experiments. Journal of Public Economics, 3(3), 291-304. http://dx.doi.org/10.1016/0047-2727(88)90043-6

Bardsley, N. (2008). Dictator game giving: altruism or artefact? Experimental Economics, 11(2), 122-133. http://dx.doi.org/10.1007/s10683-007-9172-2

Bolton, G. E., Katok, E., \& Zwick, R. (1998). Dictator game giving: Rules of fairness versus acts of kindness. International Journal of Game Theory, 27(2), 269-299. http://dx.doi.org/10.1007/s001820050072

Bolton, G. E., \& Ockenfels, A. (2000). ERC: A theory of equity, reciprocity, and competition. American Economic Review, 90(1), 166-193. http://dx.doi.org/10.1257/aer.90.1.166

Cadsby, C. B., \& Maynes, E. (1998). Gender and free riding in a threshold public goods game: Experimental evidence. Journal of Economic Behavior \& Organization, 34, 603-620. http://dx.doi.org/10.1016/S0167-2681(97)00010-3

Croson, R. T. (1996). Partners and strangers revisited. Economics Letters, 53(1), $25-32$. http://dx.doi.org/10.1016/S0165-1765(97)82136-2

Falk, A., Fehr, E., \& Fischbacher, U. (2003). On the nature of fair behavior. Economic Inquiry, 41(1), 20-26. http://dx.doi.org/10.1093/ei/41.1.20

Falk, A., Fehr, E., \& Fischbacher, U. (2008). Testing theories of fairness - intentions matter. Games and Economic Behavior, 62(1), 287-303. http://dx.doi.org/10.1016/j.geb.2007.06.001

Falk, A., \& Fischbacher, U. (2006). A theory of reciprocity. Games and Economic Behavior, 54(2), $293-315$. http://dx.doi.org/10.1016/j.geb.2005.03.001

Fehr, E., \& Fischbacher, U. (2002). Why social preferences matter? The impact of non-selfish motives on competition, cooperation and incentives. Economic Journal, 112(478), C1-C33. http://dx.doi.org/10.1111/1468-0297.00027

Fehr, E., \& Gächter, S. (1998). Reciprocity and economics: The economic implications of homo reciprocans. European Economic Review, 42(3-5), 845-859. http://dx.doi.org/10.1016/S0014-2921(97)00131-1

Fehr, E., \& Schmidt, K. M. (1999). A theory of fairness, competition, and cooperation. Quarterly Journal of Economics, 11(3), 817-868. http://dx.doi.org/10.1162/003355399556151

Fischbacher, U. (2007). z-tree: Zurich toolbox for ready-made economic experiments. Experimental Economics, 10(2), 171-178. http://dx.doi.org/10.1007/s10683-006-9159-4

Forsythe, R., Kennan J., \& Sopher, B. (1991). An experimental analysis of strikes in bargaining games with one-sided private information. American Economic Review, 81(1), 253-278.

Henrich, J., Boyd, R., Bowles, S., Camerer, C., Fehr, E., Gintis, H., \& McElreath, R. (2001). In search of homo economicus: Behavioral experiments in 15 small-scale societies. American Economic Review, 91(2), 73-78. http://dx.doi.org/10.1257/aer.91.2.73

Hoffman, E., McCabe, K., Shachat, K., \& Smith, V. (1994). Preferences, property rights, and anonymity in bargaining games. Games and Economic Behavior, 7(3), 346-380. http://dx.doi.org/10.1006/game.1994.1056

Keser, C., \& van Winden, F. (2000). Conditional cooperation and voluntary contributions to public goods. Scandinavian Journal of Economics, 102(1), 23-29. http://dx.doi.org/10.1111/1467-9442.00182

Laband, D. N., \& Beil, R. O. (1999). Are economists more selfish than other 'social' scientists? Public Choice, 100(1), 85-101. http://dx.doi.org/10.1023/A:1018370625789

Ledyard, J. O. (1995). Public goods: A survey of experimental research. In: Kagel, J. H., Roth, A. E. (Eds.), The Handbook of Experimental Economics, 111-194. New Jersey: Princeton Univ. Press.

Levitt, S. D., \& List, J. A. (2007). What do laboratory experiments measuring social preferences reveal about the real world? Journal of Economic Perspectives, 21(2), 153-174. http://dx.doi.org/10.1257/jep.21.2.153

Sliwka, D. (2007). Trust as a signal of a social norm and the hidden costs of incentive schemes. American Economic Review, 97(3), 999-1012. http://dx.doi.org/10.1257/aer.97.3.999

Stanley, T. D., \& Tran, U. (1998). Economics students need not be greedy: Fairness and the ultimatum game. Journal of Socio-Economics, 27(6), 657-663. http://dx.doi.org/10.1016/S1053-5357(99)80001-8 
Yezer, A. M., Goldfarb, R. S., \& Poppen, P. J. (1996). Does studying economics discourage cooperation? Watch what we do, not what we say or how we play. Journal of Economic Perspectives, 10(1), 177-186. http://dx.doi.org/10.1257/jep.10.1.177

Ziesecke, J. (2015). Context specific self-image concerns in strategic decisions, Mimeo.

\section{Notes}

Note 1: To avoid framing effects that stress the cooperative nature of the game, we abstained from the usage of cooperation-related wording. The expressions ,investment“, „partner“, and ,joint“" were not in the experiment. Instead we used „contribution to a project“ and „the other participant“. The experiments were conducted in German; all translations in this text are as close as possible to the German original.

Note 2: Each experimental point was valued at 0.05 Euro. All participants received a show-up fee of 2.50 Euro. The average payoff for a participant was 9.60 Euro. The average duration of an experiment session was 49 minutes. The lowest remuneration was 4.00 Euro and the highest 13.50 Euro. The above remuneration figures include the 2.50 Euro show up fee.

Note 3: The German instructions are available upon request.

Note 4: Fifty-two percent of the subjects were female and $9 \%$ were not native German speakers. Sixteen percent of the subjects had been exposed to game theory before, $5 \%$ had participated in experiments.

Note 5: For all tests: ${ }^{* * *},{ }^{* *}$, and ${ }^{*}$ denote significance at $1 \%, 5 \%$, and $10 \%$ level.

Note 6: The results, summarized in Table 5 in the Appendix, with respect to occupation are in line with work by Ahmed (2008), Laband and Beil (1999), Stanley and Tran (1998), and Yezer, Goldfarb, and Poppen (1996)). With respect to gender Cadsby and Maynes (1998) did not find evidence that men and women differ in their level of cooperation, while Anderson, DiTraglia, and Gerlach (2011) did find differences in behavior.

\section{Appendix}

Table 5. Differences in major, gender, and previous knowledge

\begin{tabular}{|c|c|c|c|c|c|c|}
\hline & \multicolumn{3}{|c|}{ Major $^{\mathrm{a}}$} & \multirow{2}{*}{$\begin{array}{l}\text { Gender }^{\mathrm{b}} \\
\text { P-Value }\end{array}$} & \multicolumn{2}{|c|}{ Knowledge } \\
\hline & Test Stat. & P-Value & Test Stat. & & Test Stat. & P-Value \\
\hline Basic Partner & 1.08 & 0.1401 & 0.55 & 0.2912 & -1.28 & 0.1003 \\
\hline Practice Partner & -1.25 & 0.1056 & 1.43 & 0.0764 & -0.37 & 0.3557 \\
\hline Basic Stranger & -0.41 & 0.3400 & -0.05 & 0.4798 & -0.82 & 0.2049 \\
\hline Practice Stranger & -1.13 & 0.1211 & -0.79 & 0.2153 & -1.13 & 0.1291 \\
\hline
\end{tabular}

Notes: One-sided Wilcoxon rank-sum tests. None of the results was significant at $1 \%, 5 \%$, or $10 \%$ level.

${ }^{\mathrm{a}} \boldsymbol{H}_{1}$ : Business and economic students contribute stochastically less than other students.

${ }^{\mathrm{b}} \boldsymbol{H}_{1}$ : Male students contribute stochastically less than female students.

${ }^{\mathrm{c}} \boldsymbol{H}_{1}$ :Students without previous game theoretical knowledge contribute stochastically less than students with previous knowledge.

\section{(c) $\overline{E Y}$}

This work is licensed under a Creative Commons Attribution 3.0 License. 